\title{
REFLEXÕES SOBRE O IMPACTO DA PANDEMIA DO COVID-19 NA EDUCAÇÃO
}

\author{
REFLEXIONES SOBRE EL IMPACTO DE LA PANDEMIA DE COVID-19 EN LA \\ EDUCACIÓN
}

REFLECTIONS ON THE IMPACT OF THE COVID-19 PANDEMIC ON EDUCATION

\author{
Celso Ribeiro Campos \\ (Pontifícia Universidade Católica de São Paulo) \\ crcampos@pucsp.br
}

Andréa Pavan Perin

(Faculdade Tecnologia de Itapetininga)

andreapavanperin@gmail.com

Ana Paula Gonçalves Pita

(Universidade Estadual Paulista)

anapaulagpita@gmail.com

Recibido: $15 / 12 / 2021$

Aprobado: 18/01/2022

\section{RESUMEN}

En este artículo buscamos recopilar las publicaciones académicas realizadas en los años 2020 y 2021 que trajeron el problema de la enseñanza a distancia que de repente reemplazó a la enseñanza presencial en los años mencionados. Para ello, hicimos una búsqueda bibliográfica con la ayuda de Google Scholar y seleccionamos los tres artículos en lengua extranjera más referenciados por este buscador. Uno de estos artículos fue escrito por un investigador brasileño, otro trajo un relato de la realidad de la enseñanza en Zambia, mientras que el tercero vio sobre la educación matemática en Alemania. También hicimos una selección de artículos en portugués, que trajeron las principales ideas que trataban desde temas políticos hasta temas relacionados con el aula y el papel de las matemáticas en el contexto de la pandemia. Además, se buscaron libros publicados en 2020 y 2021 que trajeron informes e ideas de varios autores que hemos resumido aquí. Finalmente, puntuamos un poco de nuestras experiencias, tratando de hacer su conexión con los autores mencionados anteriormente.

Palabras clave: covid-19. pandemia. educación. educación matemática

\section{ABSTRACT}

In this article we seek to compile some academic publications made in the years 2020 and 2021 that brought the problem of remote teaching that suddenly replaced the face-to-face teaching in the mentioned years. To do so, we did a bibliographical search with the help of Google Scholar and selected the three articles in foreign language most referenced by this search engine. One of these articles was written by a Brazilian researcher, another brought an account of the reality of teaching in Zambia, while the third talked about mathematics 
education in Germany. We have also selected articles in Portuguese, which brought some ideas that goes from political issues to issues related to the classroom and the role of mathematics in the context of the pandemic. Additionally, we searched for books published in 2020 and 2021 that brought reports and ideas from several authors that we have shorted up here. Finally, we highlighted our experiences, trying to link them with the authors referenced earlier.

Keywords: covid-19. pandemic. education. mathematics education

\section{RESUMO}

Neste artigo, buscamos compilar as publicações acadêmicas que, nos anos de 2020 e 2021 abordaram a problemática do ensino remoto que subitamente substituiu o ensino presencial. Para tanto, fizemos uma pesquisa bibliográfica com a ajuda do Google Acadêmico e selecionamos os três artigos em língua estrangeira mais referenciados por esse buscador. Um desses artigos foi escrito por um pesquisador brasileiro, outro trouxe um relato da realidade do ensino em Zâmbia e o terceiro versou sobre a educação matemática na Alemanha. Fizemos também uma seleção de artigos em língua portuguesa, dos quais trouxemos as principais ideias que tratavam desde questões políticas até questões relacionadas à sala de aula e ao papel da Matemática no contexto da pandemia. Adicionalmente, buscamos livros publicados em 2020 e 2021 que trouxeram relatos e ideias de diversos autores que aqui resumimos. Por fim, pontuamos um pouco de nossas experiências, procurando fazer a ligação delas com os autores referenciados anteriormente.

Palavras-chave: covid-19. pandemia. educação. educação matemática

\section{Introdução}

Em maior ou menor escala, a pandemia do Covid-19 vem afetando a vida de todos ao redor do mundo. Os impactos para quem sobrevive a ela são muitos: perda de um amigo ou familiar, desemprego, queda na renda, sequelas da doença, danos psicológicos, entre outros.

Ainda imersos numa nova onda epidemiológica, provocada pela variante Ômicron, podemos dizer que o mundo já não é o mesmo. Tivemos e ainda temos de nos adaptar a novos hábitos, novas realidades, que incluem diversos tipos de restrição, de cuidados com a saúde e a higiene, de novas demandas associadas a uma vida de maior isolamento, menos contato físico e mais interação virtual.

Todos os setores da economia foram impactados, alguns mais e outros menos, mas ninguém saiu ileso. No campo da educação, os impactos foram significativos. No estado de São Paulo, o Decreto n. 64.864 de 16/03/2020 suspendeu 100\% das atividades presenciais nas escolas. Posteriormente, a Resolução n.54, de 18/03/2020 homologou a deliberação aprovada pelo Conselho Estadual, que permitia atividades pedagógicas realizadas por meio de EAD (ensino à distância) aos alunos do ensino fundamental e médio durante o período de suspensão das aulas. Na sequência, em 20/03/2020, a Resolução n. 56, Seduc-30 anunciou antecipação de férias e recesso escolar de 150 mil professores da rede estadual. Nessa resolução, foram antecipadas 2 semanas de recesso escolar que estavam previstas para o mês de julho e outras 2 semanas de recesso que ocorreriam em abril e outubro do mesmo ano. Outras resoluções se seguiram, buscando remediar problemas como a falta que a merenda escolar fazia para os alunos, a falta de equipamentos e softwares para viabilizar o ensino remoto etc. Os outros estados do país foram afetados de forma semelhante, e, subitamente, todo o país estava à mercê de uma nova realidade na educação, exigindo de todos os envolvidos uma readaptação e um aprendizado de novas tecnologias, que ainda não haviam sido experimentadas em larga escala, nem pelos professores, nem pelos alunos. Cumpre observar que o ensino superior público e privado também ficou sujeito às mesmas restrições de suspensão de aulas, assim como as escolas particulares da educação básica. 
Em agosto de 2020, o DataSenado reportou que:

Entre os quase 56 milhões de alunos matriculados na educação básica e superior no Brasil, 35\% (19,5 milhões) tiveram as aulas suspensas devido à pandemia de Covid-19, enquanto que 58\% (32,4 milhões) passaram a ter aulas remotas. Na rede pública, $26 \%$ dos alunos que estão tendo aulas online não possuem acesso à internet (Agência Senado, 2020, n.p.).

No âmbito federal, o relatório do Conselho Nacional de Educação (CNE) do Ministério da Educação (MEC) sobre diretrizes gerais para a aprendizagem híbrida indica que o Brasil já contabilizava, naquele momento, "quase 2 (dois) anos com escolas públicas e privadas fechadas, em todos os níveis, utilizando soluções remotas emergenciais permanentemente" (Brasil, 2021: 1). O documento ainda ressalta que o domínio das tecnologias digitais está pressuposto em uma das competências gerais prescritas pela Base Nacional Comum Curricular (BNCC):

5 - Compreender, utilizar e criar tecnologias digitais de informação e comunicação de forma crítica, significativa, reflexiva e ética nas diversas práticas sociais (incluindo as escolares) para se comunicar, acessar e disseminar informações, produzir conhecimentos, resolver problemas e exercer protagonismo e autoria na vida pessoal e coletiva (Brasil, 2018: 9).

Entrementes, o relatório do CNE reconhece que

Em março de 2020, sem planejamento prévio, a sociedade brasileira obrigou-se a fechar as portas das escolas para a presença física dos estudantes, buscando desenvolver novas alternativas para a oferta de atividades educacionais não presenciais. A inevitável improvisação da oferta de atividades educacionais remotas, com ou sem suporte de modernas tecnologias de informação e comunicação, corajosamente assumida pelo conjunto dos educadores brasileiros, de todos os níveis e modalidades de educação e ensino, buscou garantir, da melhor forma possível, a manutenção dos melhores níveis possíveis de aprendizagem de seus educandos (Brasil, 2021, pp. 5-6)

Por fim, objetivando superar tal fase de tensão, apreensão e improviso, o relatório antecipa um novo desafio: o oferecimento de programas remotos de ensino alternados com momentos presenciais. Nessa linha, ele propõe um processo pedagógico de Aprendizagem Híbrida. Em um tom otimista, o relatório ressalta que

[...] esta flexibilidade híbrida não representa novidade para os professores e outros educadores, considerando que, historicamente, na organização da oferta da educação escolar, sempre se alternaram momentos presenciais, em salas de aulas ou em outros ambientes de aprendizagem desenvolvidos no ambiente escolar, com momentos não presenciais de estudos realizados em casa ou em outros ambientes culturais e sociais (Idem: 8)

Cabe ressaltar que o documento considera, como Aprendizagem Híbrida, uma metodologia mediada por Tecnologias de Informação e Comunicação (TIC) para apoiar a atividade docente, com o objetivo de desenvolver competências que vão além das atividades de sala de aula. O que as caracteriza, assim, como mais motivadoras, dinâmicas e capazes de inspirar um processo contínuo de aprendizagem.

Com um ponto de vista divergente, Helene (2021), assevera que "o ambiente em uma universidade, como também nas escolas de educação básica, é o melhor a que os jovens adultos, os adolescentes e as crianças podem ter acesso" (n.p.). Segundo o autor, esse ambiente propicia elementos que não existem no $\mathrm{EaD}$, pois "oferece inúmeras possibilidades de desenvolvimento pessoal, cultural, artístico e científico que vão muito além das aulas" (ibid.). Adicionalmente, o autor pontua que "entre os problemas mais graves do EaD durante o período da presente epidemia estão os grandes danos causados aos grupos mais desfavorecidos, como já têm mostrado os muitos dados disponíveis" (ibid.).

Nesse cenário de posições contrárias, nos interessa fazer uma reflexão e relatar nossas vivências pedagógicas e acadêmicas ao longo dos anos de 2020 e 2021, bem como algumas experiências relatadas por colegas, de modo a esboçar um panorama das consequências da pandemia na educação. 
Para tentar entender algo da dimensão que representou na educação a súbita virada do ensino presencial para o remoto, nos remetemos a Penteado (2000), que já valorizava a integração da TI (Tecnologias de Informática) ao currículo e ao espaço físico das escolas, afirmando que ela promove alteração das relações de poder e tira o professor da sua zona de conforto para inseri-lo em uma zona de risco, caracterizada por um baixo índice de certeza e controle da situação de ensino. Nesse contexto, a autora entende "a zona de conforto como a dimensão da prática docente em que estão presentes a previsibilidade e o controle" (idem: 32). Com ares de premonição, Penteado (ibid.) afirma ainda que "o uso de TI na escola, como nos sugere seu uso fora dela, requer do professor uma avaliação permanente dos procedimentos adotados e disponibilidade para o engajamento num processo contínuo de atualização".

Baseado nas palavras de Penteado, podemos entender que a adoção repentina da modalidade de ensino remoto em todos os níveis escolares tirou os professores da sua zona de conforto, exigindo deles uma adaptação forçada a um novo ambiente educacional. Não obstante, nos toca refletir também sobre a adaptação do estudante a esse novo ambiente. De acordo com Helene (2021, n.p.), o ensino remoto

[...] afetou de forma gravíssima os estudantes mais desfavorecidos, muitos dos quais simplesmente abandonaram o sistema educacional, não apenas por não disporem de computadores, mas, também, de material didático e de tempo, espaço e ambiente adequados à concentração e ao estudo.

Tendo em vista essas posições, o objetivo geral deste artigo é explorar publicações acadêmicas que versem sobre os impactos da pandemia na educação, tanto do lado do professor quanto do aluno, enquanto o objetivo específico é focar nos relatos de experiências no campo do ensino-aprendizagem de Matemática. Diante disso, a metodologia que adotamos é a da pesquisa bibliográfica, conjugada com alguns relatos de experiência, entre as quais incluiremos as nossas próprias práticas.

Nos próximos tópicos, vamos descrever alguns artigos acadêmicos, explorar alguns livros publicados sobre o tema do Covid-19 na educação, aos quais vamos acrescentar nossas experiências, finalizando com um resumo das principais informações coletadas, buscando extrair delas os principais pontos positivos e negativos do ensino remoto adotado nos anos de 2020 e 2021.

\section{Artigos acadêmicos}

Uma busca feita no Google Scholar em 09/12/2021 usando as palavras-chave Covid-19 e educação resultou em cerca de 46.100 resultados, conforme se vê na imagem da Figura 1.

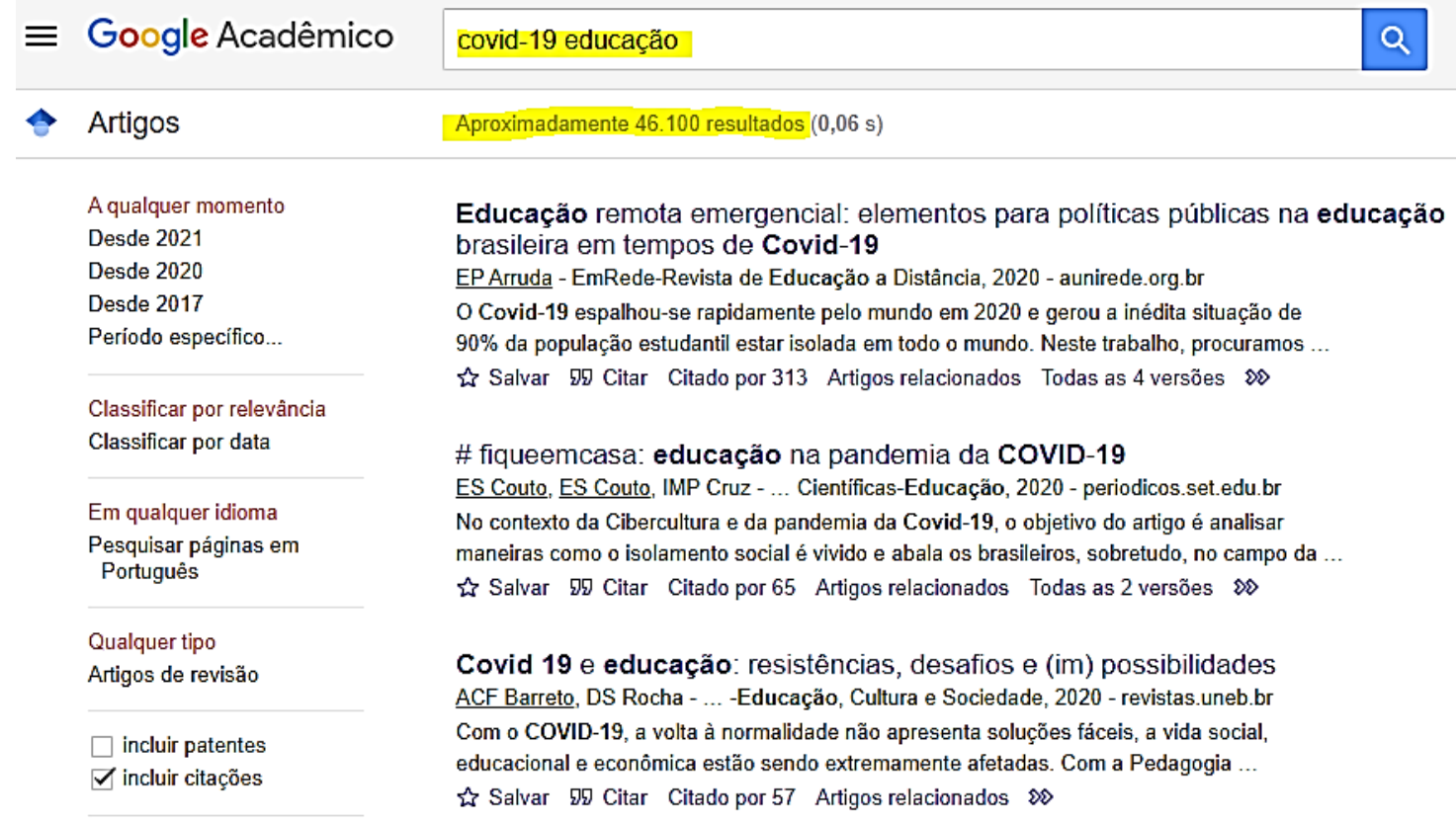


Figura 1: Artigos no Google Acadêmico

Fonte: Recuperado de: https://scholar.google.com.br/scholar?hl=pt-BR\&as_sdt=0\%2C5\&q=covid19+educa\%C3\%A7\%C3\%A3o\&btnG=. Acesso em 09/12/2021.

Como se vê na Figura 1, a ordenação requerida foi a de relevância. Se aplicarmos um filtro para publicações em língua portuguesa, o número de resultados cai para 38.800 e, se adicionarmos um filtro para publicações a partir de 2020, o número se reduz a 19.500 .

Fizemos uma outra busca atribuindo as palavras-chave Covid-19 e mathematics education, como se vê na Figura 2, o que resultou em 8.140 artigos.

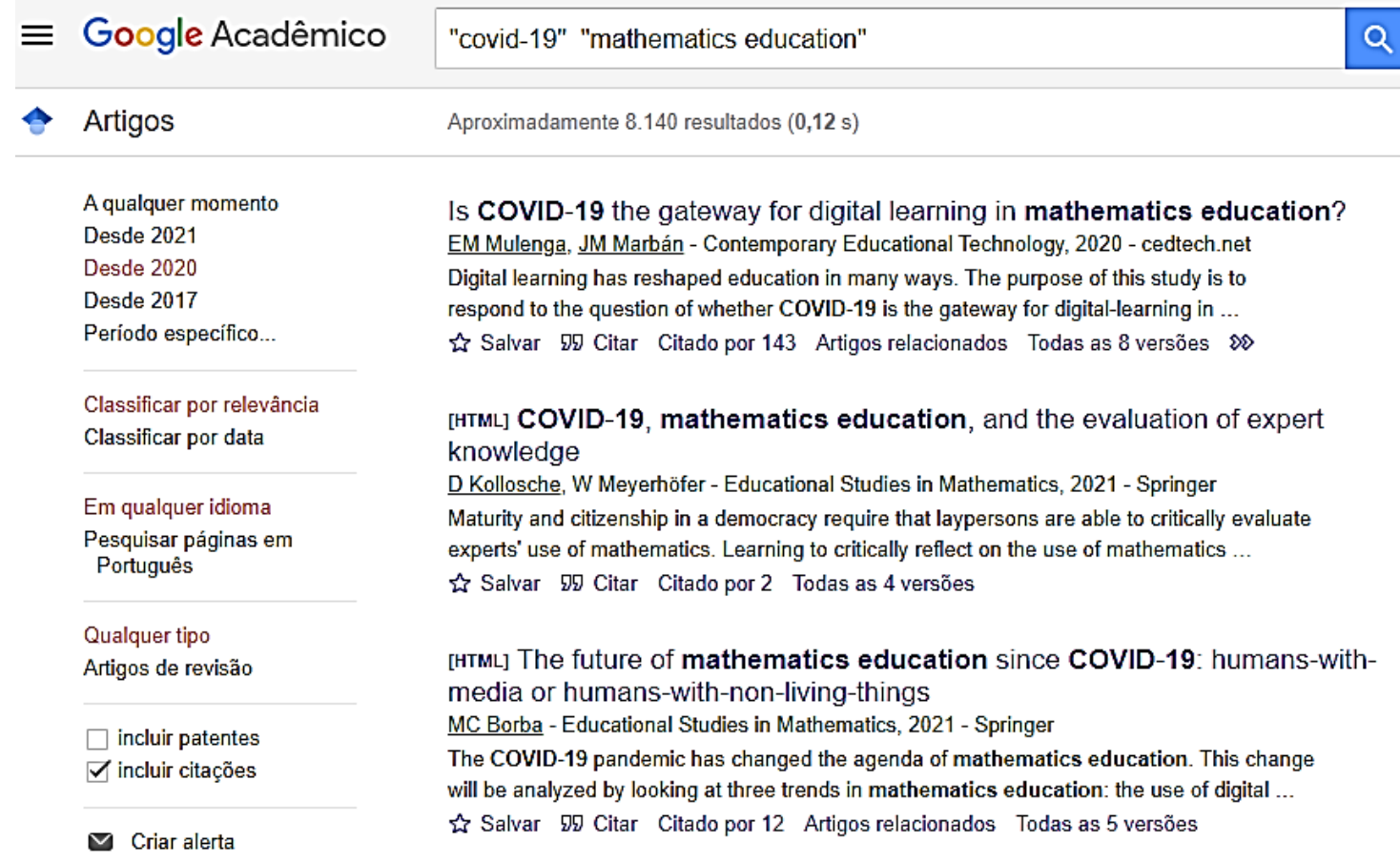

Figura 2: Artigos no Google Acadêmico em língua estrangeira

Fonte: Recuperado $\quad$ de https://scholar.google.com.br/scholar?lr=\&q=\%22covid$19 \% 22++\% 22$ mathematics+education $\% 22 \& \mathrm{hl}=$ pt-BR\&as_sdt=0,5\&as_ylo=2020. Acesso em 09/12/2021.

Diante de tantos resultados e sem a possibilidade de aplicar mais filtros, resolvemos começar explorando o artigo de Borba (2021), eminente pesquisador da área de Educação Matemática da UNESP, publicado pela Springer. O autor é largamente conhecido por suas pesquisas na área de tecnologia na Educação Matemática, sendo responsável por disseminar a expressão seres-humanos-com-mídia (Borba, 2000) e promover pesquisas que visam integrar o computador à educação matemática. Em Borba (2021), o autor discute como novas tendências em educação matemática podem surgir ou se modificar com a crise do coronavírus. Assim, ele usa o constructo teórico seres-humanos-com-mídia para conectar a crise com três diferentes tendências: o uso de tecnologias digitais, filosofia da educação matemática, e educação matemática crítica.

Em relação à primeira tendência, o autor afirma:

Se considerarmos uma tendência como um esforço para encontrar respostas para uma determinada questão, o COVID-19 avançou na agenda da tendência da tecnologia digital na educação matemática. Com a necessidade de isolamento social, tornou-se necessário oferecer educação para crianças e graduandos em casa (Borba, 2021: 388, tradução nossa).

Borba (op. cit.), afirma que embora existam diversas publicações sobre implementação de educação online em cursos de graduação, como Engelbrecht e Harding (2002, 2004, 2005), isso não se verifica no 
contexto da educação para crianças. Nessa linha, o autor pondera que a inserção da tecnologia digital na educação é, agora, um tema que concerne a todos. Adicionalmente, a amplificação da desigualdade social sob a pandemia não pode ser ignorada, assim como o surgimento do ensino remoto, o confinamento e o lockdown, podendo instigar muitos a pensar em questões filosóficas relacionadas ao lugar e ao papel do conhecimento e da aprendizagem nos seres-humanos-com-mídia.

No artigo mais referenciado na busca feita no Google Acadêmico em língua estrangeira, Mulenga e Marbán (2020) relatam o caso da adoção do ensino remoto na Zâmbia, ocorrida a partir de março de 2020 nas universidades do país:

(...) professores foram forçados a aprender métodos digitais de ensino e entrega de conteúdo aos alunos. O COVID-19 tornou-se um catalisador para a valorização de dispositivos digitais, recursos online, tecnologia de mídia social e atividades de e-learning. A literatura revela que nenhuma mudança de paradigma nos ambientes educacionais pode ser projetada com sucesso sem antes incluir professores como participantes da intenção (Mulenga \& Marbán, 2020: 2, trad. nossa).

Analogamente ao que nos propomos a fazer neste artigo, Mulenga e Marbán (ibid.) citam diversos estudos publicados em 2020 sobre a problemática da aprendizagem via métodos digitais, tais como Iwai (2020), que argumenta sobre o que os estudantes têm a ganhar ou perder nas aulas virtuais. Agnoletto e Queiroz (2020) afirmam que a lógica que permeia a conversão para o ensino-aprendizagem digital não é simples; no entanto, segundo eles, há um clamor contínuo para o lançamento de ferramentas de medidas de emergência que adotem tecnologias digitais para a educação. Roy (2020) relata estudo australiano que indica algumas plataformas úteis para ministrar aulas remotamente, enquanto o estudo de Zhao e Xu (2020), na China, preocupa-se mais com as mídias sociais como forma de disseminação de informações importantes sobre a pandemia do Covid-19.

Outros estudos, como o de Burke (2020), chamam a atenção para a necessidade de valorizar a comunicação entre os estudantes, pais e professores, via plataformas digitais, assim como garantir acesso a dados via dispositivos de armazenamento remoto (nuvem), como o Dropbox, o Google Drive e outros.

Mulenga e Marbán (2020) alertam para o fato de que estudos anteriores sobre o uso de tecnologias digitais nas aulas de Matemática indicavam que os estudantes tendem a aprender mais e melhor. Contudo, o tipo de tecnologia digital presente nesses estudos não diz respeito ao ensino remoto, configurando-se uma lacuna que os autores tentam preencher.

Mulenga e Marbán (ibid.) pesquisaram 102 futuros professores de Matemática do ensino médio, licenciandos de uma universidade de Zâmbia. Os autores reportaram os resultados de uma análise quantitativa de parte de um estudo maior sobre métodos quali-quanti. Os principais resultados apontaram que, conquanto os alunos "tenham os dispositivos digitais necessários, acesso à internet, custos de internet acessíveis e fornecimento adequado de eletricidade, eles podem obter assentos na frente da sala de aula virtual de matemática" (idem: 10). Adicionalmente, os resultados sugerem que "os futuros professores acreditam que a aprendizagem digital lhes permitirá fazer uma mudança pedagógica da matemática para um método de ensino menos formalizado que seja divertido e interessante, ao invés de rigoroso e tradicional" (ibid.).

O trabalho de Kollosche e Meyerhöfer (2021) também está entre os mais citados na lista do Google Acadêmico. Os autores investigaram conceitos matemáticos envolvidos em discussões a respeito da pandemia de Covid-19 na Alemanha, tais como taxas de mortalidade, crescimento exponencial e outros. Após identificarem os conceitos, os autores examinaram até que ponto eles podem ser entendidos por leigos. Nessa linha, eles classificaram como conceitos ideais (básicos) aqueles que podem ser entendidos por leigos, mas pontuaram que apenas os conceitos estatísticos levam a um juízo apurado dos dados reais. Nesse sentido, os autores percebem que a falta de entendimento dos conceitos estatísticos leva a concepções errôneas e manipulação. A conclusão é que a avaliação de conceitos matemáticos avançados não é possível para leigos que não desenvolveram um letramento apropriado, abrindo espaço para intepretações equivocadas. 
[...] notamos que enfrentamos debates políticos altamente relevantes e controversos, cujos componentes matemáticos não podem ser compreendidos por leigos matemáticos ao ponto de permitir a avaliação de tal conhecimento especializado. Adicionalmente, as matérias veiculadas na mídia geralmente não facilitam tal avaliação e muitas vezes fornecem relatos problemáticos dos respectivos conceitos matemáticos. Assim, o jornalismo espelha as limitações dos leigos matemáticos e não parece investir sistematicamente em uma reflexão mais profunda da matemática envolvida (Ibid.: 414)

Diante disso, apesar de defenderem os princípios da Educação Matemática Crítica preconizados por Skovsmose (1994) e Fischer (2001), eles entendem que "a reflexão crítica da matemática não pode ser a única solução para o problema enfrentado, pois muitas vezes a matemática em questão está fora do alcance do leigo matemático" (ibid: 415, trad. nossa).

Tendo em vista as ponderações de Kollosche e Meyerhöfer (2021) acerca da importância do conhecimento estatístico para a compreensão de dados e informações sobre a pandemia veiculados nos diversos tipos de mídia, selecionamos o artigo de Samá et al. (2020), que traz reflexões sobre o papel da Educação Estatística na formação de professores no contexto da vida em tempos de Covid-19. Os autores vão ao encontro do que afirmam Kollosche e Meyerhöfer (2021) e asseveram que

\begin{abstract}
A crise sanitária vivenciada pela humanidade evidencia a importância da ciência, em especial da Matemática e da Estatística, na compreensão da Pandemia da Covid-19. Mais do que apenas a compreensão de números e padrões, este fenômeno traz em seu bojo a necessidade de romper os muros da disciplinaridade e a necessidade da transversalidade (Samá et al., 2020: 437).
\end{abstract}

Nessa linha, os autores citam Cobb e Moore (1997), para quem a Estatística fornece métodos e técnicas de análise de dados capazes de favorecer outros campos da ciência.

Acompanhando as informações divulgadas na mídia sobre a Pandemia da Covid-19, percebemos a relevância da Estatística na sua compreensão por parte da população, no auxílio da tomada de decisão e no planejamento de estratégias por parte dos gestores públicos a fim de conter a disseminação desta doença (Samá et al., 2020: 441).

Os autores buscam refletir sobre como os professores podem trabalhar em suas aulas alguns conhecimentos de Estatística, Matemática e Epidemiologia por meio do estudo de seis casos de ensino que ocorreram no contexto da pandemia do Covid-19. Eles analisam casos envolvendo números absolutos versus números relativos, representações gráficas, aplicação de escala logarítmica, função exponencial, gráficos em Geogebra etc.

Os dados gerados pela pandemia da Covid-19 proporcionam uma oportunidade ímpar para o professor da Educação Básica contextualizar os conceitos de Estatística, focando na importância do letramento estatístico, do conhecimento matemático e da leitura dos dados, bem como a capacidade de analisar e interpretar estes de forma crítica (ibid: 448).

Os autores entendem que a compreensão de conceitos de Matemática, Estatística e Epidemiologia são fundamentais para conscientizar a população sobre medidas de prevenção que envolvem, por exemplo, o distanciamento social. "Compreender como os dados são gerados, saber ler e interpretar gráficos e entender o processo de modelagem de variáveis estatísticas é fundamental para promover o letramento estatístico e o senso crítico dos estudantes (ibid., p; 448).

Entre os artigos em língua portuguesa, nos pareceu relevante a publicação de Saviani e Galvão (2021), já que aquelas que aparecem como mais citadas na Figura 1 datam de 2020. Os autores discutem as implicações pedagógicas do ensino remoto e consideram falacioso o discurso de adesão por falta de alternativa. Por meio da explicitação dos elementos constitutivos da tríade conteúdo-forma-destinatário, eles buscam demonstrar a inviabilidade de uma educação remota de qualidade e apresentam algumas proposições que poderiam ter sido adotadas. E chamam a atenção para a elevação da carga de trabalho a que os docentes foram submetidos durante a pandemia, que, segundo eles, ocorreu em condições desfavoráveis: 
Relevante destacar também que esse processo açodado de implementação do ensino remoto contribui para a intensificação do adoecimento docente. Pois, além da pressão e vigilância impostas que podem se configurar em assédio, o uso constante das tecnologias, com as quais nem todos são familiarizados, amplia as possibilidades de adoecimento físico e mental (Informandes, 2020: 12, apud Saviani \& Galvão, 2021: 43).

Diante disso, os autores sugerem que "havendo disponibilização de acesso e equipamentos, poderiam ser criados espaços de encontros virtuais nas escolas" (Saviani \& Galvão, 2021: 44), com o objetivo de "promover debates sobre as crises em curso e o papel da educação, além de outras atividades culturais, cursos livres, seminários etc., que mantenham os vínculos com a comunidade escolar" (ibid: 44). Em relação ao calendário escolar, os autores sugerem o seu cancelamento, tendo em vista o período de exceção, sem a adoção do chamado ensino remoto.

\begin{abstract}
Aliás, essa reorganização do calendário foi tardiamente estabelecida pela Lei n ${ }^{\circ} 14.040$, de 18 de agosto de 2020. Por outro lado, é inegável que a lei incentiva o "ensino" remoto, da educação infantil ao ensino superior. Contudo, a Lei n⿳ 14.040/2020 (BRASIL, 2020) não determina a adoção das "atividades pedagógicas não presenciais" e apenas permite que sejam desenvolvidas (ibid: 44, grifo dos autores).
\end{abstract}

Tamayo e Tuchapesk da Silva (2020) baseiam-se em estudiosos que associam uma crise da educação escolar ao esgotamento do chamado projeto da Modernidade/Colonialidade. E argumentam em favor de pensar-se uma Educação (Matemática) que não se submeta a ele, mas que, em movimentos de desobediência político-epistêmica, estude os conhecimentos matemáticos ligados a cosmogonias não ocidentais.

[...] a escola, entendida como instituição do aparelho do Estado, já antes da pandemia enfrentava diversas problemáticas considerando a desigualdade social, os fatores históricos, políticos e econômicos do Brasil, que tornaram-se ainda mais graves com a chegada do "Covid-19” [...] (ibid: 31, aspas do autor).

As autoras entendem que a crise da educação escolar pode se aprofundar com a adoção deliberada do ensino remoto, na medida em que pensar a educação escolar nesse contexto, especificamente no ensino de Matemática, implica em atender algumas necessidades mínimas para o desenvolvimento do trabalho dos professores, ao mesmo tempo em que limita a possibilidade de aprendizagem dos alunos. Adicionalmente, elas chamam a atenção para o fato de que não devemos ignorar que "muitos estudantes e educadores, principalmente, da rede pública de ensino, não têm acesso à internet ou computador em casa e, ainda, que nem todos os professores e alunos sabem usar plataformas de ensino virtuais" (ibid: 36).

As autoras trazem imagens e falas para demonstrar seus pontos de vista, conforme Figura 3.

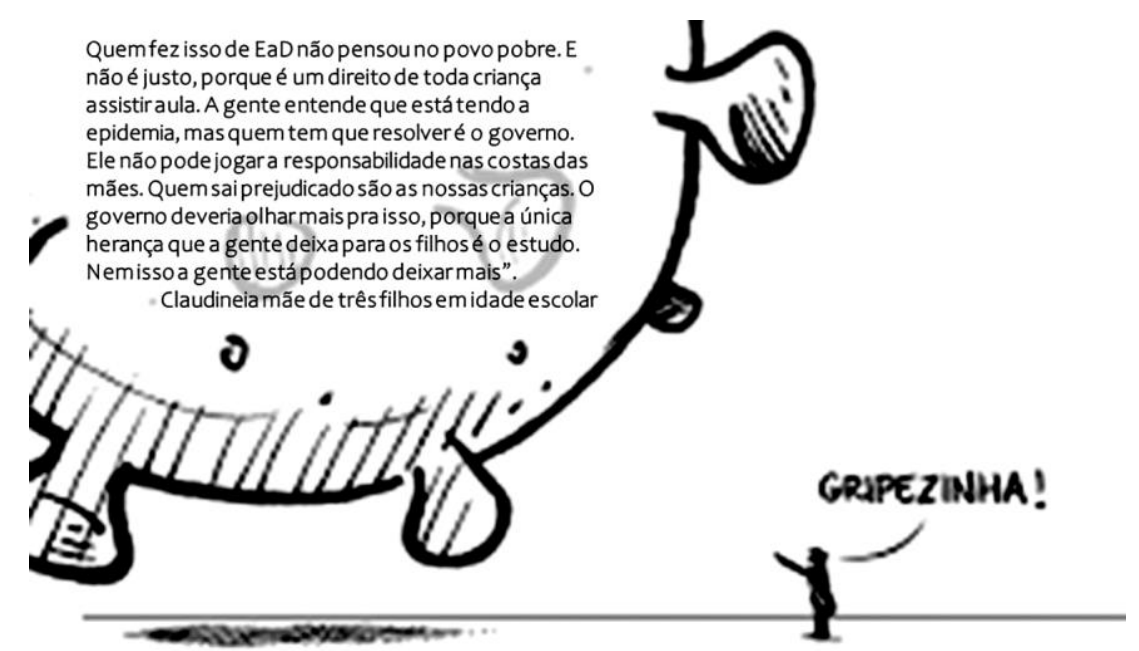

Figura 3: Escola em crise.

Fonte: Recuperado de "Desafios e possibilidades para a Educação (Matemática) em tempos de "Covid-19" numa escola em crise,” de C. Tamayo, M.Tuchapesk da Silva, 2020, Revista Latinoamericana de Etnomatemática, 13, 1: 29-48. 


\begin{abstract}
"Oi professora, tudo bem? [...] Sem você professora, eu não consigo aprender bem. A mãe não é igual você. Você tem as manias de "pro". A minha mãe não tem. Ela trabalha num restaurante, ela só tem mania de fazer comida. Desculpe incomodar agora, mas eu queria falar para senhora isso". [Áudio de aluno enviado para professora]. (Tamayo \& Tuchapesk da Silva, 2020: 37).
\end{abstract}

Mesclando falas que consideram favoráveis à ideia de ensino remoto a outras que problematizam o acesso à internet, as autoras buscam tensionar e pensar de diferentes formas os desafios e possibilidades da Educação (Matemática) em tempos de pandemia, temperando a abordagem com discussões sociais, políticas e econômicas, assim como com movimentos ativistas que denunciam a pobreza sistêmica e a negação de assistência sanitária, contrapondo-se, ainda, "à falsa narrativa moral nacionalista religiosa" (ibid: 45).

\title{
Livros
}

Diversas publicações abordando a pandemia de Covid-19 no Brasil foram lançadas no período pesquisado, em perspectivas as mais diversas. Campos e Perin (2020), por exemplo, faz um estudo quantitativo da evolução da pandemia no primeiro semestre de 2020; Matta et al. (2021) analisa os impactos sociais da Covid-19 no Brasil entre as populações vulnerabilizadas; e Harari (2020) traz notas sobre a pandemia e discute lições para o mundo pós-coronavírus; entre outros.

Para este artigo, comentaremos dois livros, intitulados Pandebook: cabeças pensantes na pandemia, volume 1 (Sevarolli \& Kistemann Junior, 2020) e volume 2 (Kistemann Junior \& Sevarolli, 2021). Ambos apresentam coletâneas de artigos de diversos autores, dentre os quais abordaremos os que versam sobre a educação.

O volume é dividido em duas partes, sendo que a primeira é sobre "Educação e Pandemia". Desta parte, selecionamos dois artigos: Flores (2020) e Reis (2020).

Flores (2020) investiga o ensino superior no Brasil em tempos de pandemia. Ainda sentindo os primeiros impactos da suspensão das aulas nas universidades privadas e públicas, a autora questiona como serão feitas as reposições de carga horária, discutindo como o ingresso de novas turmas é afetado, e como as Instituições de Ensino Superior (IES) podriam se preparar para outros imprevistos. A autora parece antever a seriedade do problema que se instaurou nas universidades públicas (principalmente), as quais até o final de 2021, ainda não haviam conseguido equilibrar a reposição de aulas, comprometendo o calendário de 2022 e acumulando ao menos três anos de prejuízo para os envolvidos.

Reis (2020) faz reflexões sobre a educação matemática em tempos de pandemia e nota como conceitos matemáticos e estatísticos se tornaram importantes, sendo buscados com frequência na internet. Segundo o autor, a palavra "gráfico" apresentou, em março de 2020, um aumento de 100\% na sua busca indicada pelo Google Trends, quando comparada com o mesmo período do ano anterior. Isso também ocorreu com os termos "exponencial" e "curva".

\footnotetext{
Nesse ponto, é preciso fazer uma pausa e refletir sobre a necessidade real de tratar desse problema sanitário e social gravíssimo como um mero problema de matemática. Não estaremos nesse caso banalizando a vida? Será mesmo que essa possibilidade de "contextualização" do problema é benéfica em termos de aprendizagem? É mais do que necessário pensar antes de qualquer outra coisa no fator humano. Matematizar a vida do ser humano não parece ser um caminho que faça o estudante ter maior interesse pela matemática. Pelo contrário, pode ser ainda mais traumático para pessoas que já sofreram a perda de entes queridos (ibid: 60).
}

No volume 2, Santiago (2021) expõe que a pandemia acelerou processos que vinham se descortinando lentamente no cenário educacional e que o ensino remoto emergencial trouxe aos alunos com deficiência novos desafios, somados aos já existentes. Nesse contexto, ela cita o Programa Incluir e o Projeto de 
Acessibilidade Curricular, que surgiram como desdobramentos de um projeto de extensão anterior e que visam ajudar a superar esses novos desafios.

Já Costa (2021) identifica uma tensão entre a vida e a liberdade na educação em tempos de pandemia, a qual ele chama de educação pandêmica. $\mathrm{O}$ autor busca demonstrar, em seu artigo, que a contemporânea apreensão vulgar do sentido da liberdade não possui sustentação no pensamento liberal. A forma como a parte negacionista da massa popular compreende a liberdade se mostra fundamental para o entendimento da modulação das forças políticas que deságuam, inclusive, na política educacional, nesses tempos de pandemia.

Gabriel (2021) destaca que o novo jeito remoto de realizar o ensino e a aprendizagem foi instalado de um modo drástico e repentino. Os docentes precisaram rever seus planos de ensino, adaptar, criar, lidar com o ambiente virtual, pensar em novas estratégias pedagógicas e metodológicas. Além de todas essas demandas, a autora pondera que houve a necessidade de construção de uma nova competência: o uso proficiente de tecnologias digitais. $\mathrm{O}$ texto discute as dificuldades que o professor de Atendimento Educacional Especializado (AEE) precisa transpor para que a docência possa ser realizada com êxito e para que o aluno compreenda o conteúdo ensinado.

Medeiro (2021) busca analisar e contrastar, no ensino tradicional e no ensino-aprendizagem exploratório, uma aula de Matemática. As mudanças nos papéis e na concepção sobre o conhecimento matemático, nesses dois modelos, são fundamentais para a compreensão do que realmente muda ou não muda, nas complexas interações da sala de aula. A autora discute, então, a transição da matematofobia para a matematofilia.

Rosa e Orey (2021) avaliam a passagem do processo educacional da presencialidade para a virtualidade, ponderando que esse movimento foi um desafio para os docentes e discentes, pois, durante o período, a aprendizagem de conteúdos escolares foi sendo realizada sem que os professores tivessem uma capacitação específica para trabalhar remotamente. Segundo os autores, a crise provocada pela Covid19 terá efeitos de longo alcance no campo educacional, pois a pandemia causou a maior interrupção de sistemas educacionais da história da humanidade, afetando cerca de 1,6 bilhão de alunos, em mais de 190 países.

\section{Nossas experiências e considerações finais}

Alguns relatos presentes nas publicações analisadas têm relação com nossa experiência docente, tanto no ensino médio quanto no ensino superior (público e privado). Nossas principais dificuldades se deram no início do período da interrupção das aulas presenciais, quando tivemos apenas uma semana para nos adaptarmos a novas plataformas de ensino virtual (Teams, Zoom, Moodle), fato que corrobora as ideias apresentadas por Gabriel (2021) e por Agnoletto e Queiroz (2020)

Adicionalmente, percebemos a problemática evidenciada por Tamayo e Tuchapesk da Silva (2020), que problematizaram a desigualdade social no ambiente de ensino remoto. Em uma de nossas aulas de ensino superior em uma universidade privada do estado de São Paulo, um aluno inadvertidamente abriu sua câmera e, sem perceber, deu a todos os demais colegas a visão de seu entorno, o qual parecia ser um barraco muito humilde. Não podemos avaliar se tal fato lhe causou constrangimento, mas a aula seguiu seu curso sem menção alguma ao ocorrido. Tendo a universidade uma predominância de alunos provenientes das classes mais abastadas, com alguns poucos alunos bolsistas, é possível inferir algum incômodo que o aluno mais humilde possa ter sentido.

Nossas experiências não nos levam a concordar com Saviani e Galvão (2021), para quem as aulas deveriam ter sido suspensas ao longo de todo o período de pandemia, sem a migração para o ambiente remoto. Percebemos, em nossas aulas, uma crescente ambientação no ambiente virtual, o qual passou a ser encarado com naturalidade por todos os atores que, ainda no ano de 2021, vivenciavam essa realidade. 
Não obstante, vimos pesquisas acadêmicas serem adiadas e/ou interrompidas por conta da impossibilidade da escola pública de adotar com eficácia o ensino remoto, já que os alunos não tinham acesso à internet ou não tinham os equipamentos eletrônicos necessários. Nesse caso, observamos sérios prejuízos para ambas as partes, principalmente para os alunos, na mesma linha que asseverou Tamayo e Tuchapesk da Silva (2020).

Na outra ponta se situou o trabalho de Kollosche e Meyerhöfer (2021), que pontuaram que, na Alemanha, a principal preocupação com a educação na pandemia dizia respeito aos conceitos matemáticos e estatísticos necessários para entender as informações veiculadas pela mídia local. Os autores não fizeram menção a possíveis dificuldades enfrentadas pelos professores e/ou pelos alunos, evidenciando a face da pandemia em países desenvolvidos.

Por fim, destacamos a reflexão de Reis (2020), a qual nos parece bastante apropriada e nos remete a um fato que muitas vezes parece controverso, ao comentar sobre a discussão de conceitos matemáticos e estatísticos em tempos de pandemia, fazendo um contraponto às ideias de Kollosche e Meyerhöfer (2021): O professor de Matemática é um profissional de Humanas, não de Exatas! Nesse contexto, o autor nos faz pensar sobre qual seria a fronteira entre o humano e a ciência!

\section{Referências}

Agência Senado, Elisa Chagas. (2020). DataSenado: quase 20 milhões de alunos deixaram de ter aulas durante pandemia. Recuperado de: https://www12.senado.leg.br/noticias/materias/2020/08/12/datasenado-quase-20-milhoes-de-alunosdeixaram-de-ter-aulas-durante-pandemia

Agnoletto, R., \& Queiroz, V. (2020). COVID-19 and the challenges in Education. Recuperado de https://www.researchgate.net/publication/340385425

Burke, J. (2020). Covid-19 Practice in Primary Schools in Ireland Report. Recuperado de: https://doi.org/10.13140/RG.2.2.14091.03369

Borba, M. C. (2000). "GPIMEM e UNESP: pesquisa, extensão e ensino em informática e educação matemática”. In M.G. Penteado \& M.C. Borba (Coords), A informática em ação: formação de professores, pesquisa e extensão. 47-66. Olho d’Água. São Paulo.

Borba, M. C. (2021). "The future of mathematics education since COVID-19: humans-with-media or humans-with-non-living-things". Educational Studies in Mathematics. Springer. 108. 385-400. https://doi.org/10.1007/s10649-021-10043-2

Brasil. (2018). Base Nacional Comum Curricular: educação é a base. MEC. Brasília. Recuperado de: http://basenacionalcomum.mec.gov.br/

Brasil. (2021). Diretrizes gerais sobre aprendizagem híbrida. CNE/MEC. Brasília. Recuperado de: http://portal.mec.gov.br/index.php?option=com_docman\&view=download\&alias=227271-texto-

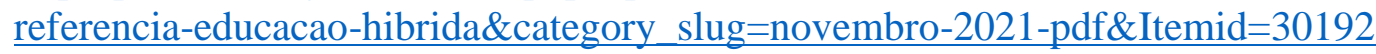

Campos, C. R., \& Perin, A. P. (2020). Covid-19: um estudo comparativo da pandemia no Brasil e na Itália. Editora da UFCSPA. Porto Alegre.

Costa, F. R. (2021). "Educação pandêmica entre a liberdade e a vida: uma crítica para a moderna, mas profundamente idiotizante, apreensão estereotipada da liberdade". In M. A. Kistemann Junior \& F. C. Sevarolli (Coords.). Pandebook: cabeças pensantes na pandemia. Volume 2. 121-137. Taubaté: Akademy. 
Decreto n. 52, de 17 de março de 2020. "Dispõe sobre a adoção de medidas adicionais, de caráter temporário e emergencial, de prevenção de contágio pelo COVID-19 (Novo Coronavírus), e dá providências correlatas". Recuperado de: http://diariooficial.imprensaoficial.com.br/nav v5/index.asp?c=4\&e=20200317\&p=1

Engelbrecht, J., \& Harding, A. (2002). "A qualitative investigation on the impact of web-based undergraduate mathematics teaching on developing academic maturity". Technical Report UPWT. 13.

Engelbrecht, J., \& Harding, A. (2004). "Combining online and paper assessment in a web-based course in undergraduate mathematics". Journal of Computers in Mathematics and Science Teaching. 23(3). $217-231$.

Engelbrecht, J., \& Harding, A. (2005). "Teaching undergraduate mathematics on the Internet". Educational Studies in Mathematics. 58. 253-276.

Fischer, R. (2001). Höhere Allgemeinbildung [Higher general education]. In R. Aulke, A. Fischer-Buck \& K. Garnitschnig (Coords.). Situation: Ursprung der Bildung. 151-161. Leipziger Universitätsverlag Leipzig.

Flores, A. P. X. (2020). "O ensino superior no Brasil em tempos de pandemia". In F. C. Sevarolli \& M. A. Kistemann Junior (Coords.), Pandebook: cabeças pensantes na pandemia Volume 1. 43-52. Akademy. Taubaté.

Gabriel, K. A. (2021). "Atendimento educacional especializado na educação básica: reinventando saberes e práticas durante a pandemia". In M. A. Kistemann Junior \& F. C. Sevarolli (Coords.), Pandebook: cabeças pensantes na pandemia Volume 2. 155-168. Akademy. Taubaté.

Harari, Y. N. (2020). Notas sobre a pandemia: E breves lições para o mundo pós-coronavírus (artigos e entrevistas). Companhia das Letras. São Paulo.

Helene, O. (2021). "Alguns fatos e algumas considerações sobre o ensino a distância”. Jornal da USP. Recuperado de: https://jornal.usp.br/?p=477724

Informandes. (2020). Ensino remoto em substituição ao presencial? Recuperado de: https://issuu.com/andessn/docs/informandes___julho_2020__hi

Iwai, Y. (March 13, 2020) 'Online Learning during the COVID-19 Pandemic: What do we gain and what do we lose when classrooms go virtual?'. Recuperado de: https://blogs.scientificamerican.com/observations/online-learning-during-the-covid-19-pandemic/

Kollosche, D., \& Meyerhöfer, W. (2021). "Covid-19, mathematics education, and the evaluation of expert knowledge". Educational Studies in Mathematics. 108. 401-417. Springer. Retirado em 13/12/2021 de: https://doi.org/10.1007/s10649-021-10097-2

Lei $n$. 14.040, de 18 de agosto de 2020. Estabelece normas educacionais excepcionais a serem adotadas durante o estado de calamidade pública reconhecido pelo Decreto Legislativo $\mathrm{n}^{\circ}$ 6, de 20 de março de 2020; e altera a Lei no 11.947, de 16 de junho de 2009. Diário Oficial da União. Retirado em 25/10/2020 de: https://www.in.gov.br/en/web/dou/-/lei-n-14.040-de-18-de-agosto-de-2020-272981525

Matta, G. C., Rego, S., Souto, E. P., \& Segata, J. (eds.). (2021). Os impactos sociais da Covid-19 no Brasil: populações vulnerabilizadas e respostas à pandemia. Série Informação para ação na Covid-19. Rio de Janeiro: Observatório Covid 19. Editora FIOCRUZ. Recuperado de: https://doi.org/10.7476/9786557080320. 
Medeiros, K. M. (2020) “A Aula de Matemática Durante a Pandemia do Covid-19 no Brasil: Aumentar a Matematofobia ou contribuir para Matematofilia?” In M. A. Kistemann Junior \& F. C. Sevarolli (Coords.), Pandebook: cabeças pensantes na pandemia Volume 2. 171-191. Akademy. Taubaté

Mulenga, E. M., \& Marbán, J. M. (2020). Is COVID-19 the Gateway for Digital Learning in Mathematics Education? Contemporary Educational Technology. $12(2) . \quad 1$ 11. https://doi.org/10.30935/cedtech/7949

Penteado, M. G. (2000). "Possibilidades para a formação de professores de Matemática". In M. G. Penteado \& M.C. Borba (Coords.). A informática em ação: formação de professores, pesquisa $e$ extensão. 23-34. Olho d'Água. São Paulo.

Reis, E. L. (2020). "Reflexões sobre educação matemática em tempos de pandemia". In F. C. Sevarolli \& M. A. Kistemann Junior (Coords.), Pandebook: cabeças pensantes na pandemia Volume 1. 55-67. Taubaté: Akademy.

Resolução n.54, de 18 de março de 2020. Altera dispositivos da Resolução SE 25, de 17-03- 2020, que dispõe sobre a jornada laboral mediante teletrabalho, em regulamentação ao Decreto 64.864, de 16-032020. Recuperado de: https://www.imprensaoficial.com.br/DO/BuscaDO2001Documento_11_4.aspx?link=\%2f2020\%2fexec utivo\%2520secao\%2520i\%2fmarco\%2f19\%2fpag_0018_0a82bd5d0fbe115a6a01b37f3c32f5cc.pdf\&p $\underline{\text { agina }}=18 \&$ data $=19 / 03 / 2020 \&$ caderno $=$ Executivo $\% 20 I \&$ paginaordenacao $=100018$

Resolução n.56, de 20 de março de 2020. Estabelece diretrizes para a organização e funcionamento do Ensino Fundamental e do Ensino Médio da Educação de Jovens e Adultos - EJA em classes multisseriadas, e dá providências correlatas. Recuperado de: https://www.imprensaoficial.com.br/DO/BuscaDO2001Documento_11_4.aspx?link=\%2f2020\%2fexec utivo\%2520secao \% 2520i\%2fmarco\%2f21\%2fpag 0022 b6b0bd8df32b49cff25f5a6274f757bf.pdf\&p agina $=22 \&$ data $=21 / 03 / 2020 \&$ caderno=Executivo \%20I $\&$ paginaordenacao=100022.

Rosa, M., \& Irey, D. C. (2020) "Educação matemática, pandemia e modelagem matemática: oportunidades de aprendizagem em tempos de crise". In M. A. Kistemann Junior \& F. C. Sevarolli (Coords.), Pandebook: cabeças pensantes na pandemia Volume 2. 195-216. Akademy. Taubaté.

Roy, D. (2020). Trying to homeschool because of coronavirus? Here are 5 tips to help your child learn. March. Recuperado de: https://theconversation.com/trying-to-homeschool-because-of-coronavirushere-are-5-tips-to-help-your-child-learn-133773

Samá, S., Cazorla, I., Velasque, L., Diniz, L., \& Nascimento, L. (2021). "Reflexões sobre o papel da educação estatística na formação de professores no contexto da pandemia do Covid-19”. Jornal Internacional de Estudos em Educação Matemática, 13 (4), esp. 437-449. Retirado em 13/12/2021 de: Reflexões Sobre o Papel da Educação Estatística na Formação de Professores no Contexto da Pandemia da Covid-19 | Jornal Internacional de Estudos em Educação Matemática (pgsskroton.com)

Santiago, M. C. (2021). “A educação em contexto de pandemia: reinventado projetos formativos e processos de ensino-aprendizagem”. In M. A. Kistemann Junior \& F. C. Sevarolli (Coords.), Pandebook: cabeças pensantes na pandemia Volume 2. 109-117. Akademy. Taubaté.

Saviani, D., \& Galvão, A. C. (2021). "Educação na pandemia: a falácia do "ensino" remoto". Universidade $e \quad$ Sociedade. 31(67). 36-49. Recuperado de: https://www.andes.org.br/img/midias/0e74d85d3ea4a065b283db72641d4ada_1609774477.pdf

Sevarolli, F. C., \& Kistemann Junior, M. A. (orgs.). (2020). Pandebook: cabeças pensantes na pandemia. Volume 1. Akademy. Taubaté. 
Skovsmose, O. (1994). Towards a philosophy of critical mathematics education. Kluwer. Amsterdam.

Tamayo, C., \& Tuchapesk da Silva, M. (2020). "Desafios e possibilidades para a Educação (Matemática) em tempos de "Covid-19" numa escola em crise". Revista Latinoamericana de Etnomatemática, 13(1). $29-48$.

Zhao, Y., \& Xu, H. (2020). Chinese Public Attention to COVID-19 Epidemic: Based on Social Media. Recuperado de: https://doi.org/10.1101/2020.03.18.20038026 